bibliográficas y hemerográficas. De esta forma, nos aproxima a algunos de los acontecimientos más significativos de su vida y trayectoria gracias a la recuperación de un buen número de datos relativos a su vida profesional en todo el mundo.

La colección, antes citada, de epístolas que María Barrientos envió a José Bilbao entre 1905 y 1906 fundamentan el tercer capítulo. En primer lugar, las presenta transcritas tras hallarlas en la Biblioteca de Cataluña de Barcelona para, a continuación, efectuar un estudio crítico de las mismas en el que aborda su contenido de estas misivas, el contexto profesional y las alusiones personales que aparecen en ellas reflejadas como la mentalidad de la soprano. Por último, el cuarto capítulo recoge las interesantísimas conclusiones finales tras la que Sánchez Rodríguez muestra las amplias y diversas referencias bibliográficas que ha manejado.

Sin duda, se trata un libro muy recomendable y necesario que nos acerca con rigor e interés a la interesantísima figura de María Barrientos. Al mismo tiempo, evidencia la importancia y la necesidad de que la ciencia y la investigación musical, en este caso, atiendan de una vez por todas al trabajo que una gran cantidad de mujeres han desarrollado en muy diversos campos. En este sentido, hoy el camino a recorrer sigue siendo muy extenso y variado. Pese a ello, un buen número de instituciones e investigadoras de muy diversas latitudes están propiciando un cambio progresivo y necesario en pos de la igualdad de género en todos los ámbitos de la sociedad.

https://doi.org/10.32735/S0718-2201202000050801

Marco Antonio de la Ossa Martínez

Universidad de Castilla-La Mancha (España)

marco.ossa@uclm.es

\title{
Daniel QuilaQueo Rapimán y Segundo QuintriQueo Millán. Métodos Educativos Mapuches: Retos de la doble racionalidad educativa, aportes para un enfoque educativo intercultural. Centro de Investigación en Contexto Indígena (CIECH), Ediciones Universidad Católica de Temuco, 2017, 171 pp.
}

El libro aborda las tensiones epistemológicas de la doble racionalidad a la que se ven enfrentados los estudiantes mapuches. Quienes, por un lado, construyen el conocimiento mediante el kimeltuwün (acción educativa de la educación familiar), que de acuerdo con los kimches (sabios mapuches) es un proceso de aprendizaje enseñanza que se configura entre una o más personas y que cuenta con cinco principios educativos clave: kümeyawael (ser persona de buen comportamiento), yamüwael (ser persona que estima la familia y la comunidad), küme che geael (ser buena persona) y kim che geael (ser persona sabia). Estos principios están orientados desde la naturaleza, el medio social y espiritual. Así mismo, los estudiantes de origen mapuche se ven enfrentados a una educación occidental de corte eurocéntrica, con un enfoque monocultural, que comprende a la educación como un proceso de enseñanza y aprendizaje, cuyo foco central es la reproducción de información. En este contexto se tensiona el aprendizaje, porque, la educación de la escuela no considera los saberes mapuches para la 
construcción de conocimiento, sin embargo la educación mapuche asume para sí la educación occidental, logrando dos comprensiones: la escolar y la mapuche.

El libro es el resultado de una construcción epistemológica que los autores han conseguido gracias a una trayectoria empírica basada en la investigación educativa, con carácter analítico-descriptivo, complementado con una metodología fenomenológicahermenéutica. Se pone énfasis en los sujetos y su contexto, pues de esta forma se consigue disociar de los marcos colonialistas dominantes, que han imperado a la hora de investigar a la educación familiar mapuche. Esta particularidad se da en el contexto que ambos autores se han formado en la doble racionalidad educativa y que su propio günezuam (proceso de darse cuenta) les ha permitido lograr estas comprensiones.

Las dimensiones abordadas en el libro son tres. La primera tipificación corresponde a los métodos educativos mapuches a partir del saber y la experiencia de más de medio centenar de kimches. En esta dimensión los autores estudian y categorizan el kimün (contenidos), objetivos y métodos de acuerdo con las particularidades territoriales, las relaciones con el saber desde los kimches, los kuyfike zugu (conocimiento ancestral y memoria social) y los saberes escolares, con lo que configura el kimeltuwün. La segunda, es la historización de las estrategias de incorporación de los mapuches al Estado-Nación. Se describe la tensión epistemológica histórica que se ha entretejido en el intento de occidentalizar la sociedad mapuche, la que enfrenta una doble racionalidad, versus sus dominador que solo vive en una racionalidad monocultural eurocéntrica occidental. $\mathrm{La}$ tercera es la incorporación de métodos educativos mapuches a contenidos del currículum escolar, con abandono de una visión monocultural. Aquí se entrega un método educativo mapuche, denominado kimeltuwün, en respuesta para enfrentar la tensión de la doble racionalidad desde una perspectiva pragmática. El objetivo es dinamizar el currículum escolar vigente, desde una configuración contextualizada que conlleva elementos conceptuales, procedimentales y actitudinales. Esto es direccionado por principios articulatorios, así como el respeto, la estima y el reconocimiento entre los miembros de la familia y las comunidades, el buen pensamiento, la solidaridad y el principio de la persona en el saber.

Cada una de estas dimensiones entrega elementos contextuales y pragmáticos para abordar la tensión explicitada en la implementación de la educación intercultural bilingüe. La educación intercultural bilingüe cuenta con un currículum vigente desde 1994, pero que presenta evidencia de una monoculturización a la hora de materializarlo en el sistema educativo escolar, en particular en las escuelas de la región de $\mathrm{La}$ Araucanía. Es decir, es imprescindible repensar el abordaje metodológico, con enfoque intercultural, comprendiéndola como un proyecto ético, político y epistémico a construir mediante la escolarización. Por tanto, desde el punto de vista epistemológico es el pluralismo y la contextualización la que permitirán que exista una transformación de la vivencia de la interculturalidad.

El libro presenta cinco capítulos, que explicitan la tensión de la doble racionalidad educativa, mediante los relatos y testimonios de los sabios, por último, 
configurar una respuesta al quiebre epistemológico, como es la implementación de los métodos educativos mapuches. Respecto del contenido el libro se articula en cinco capítulos. En el primer capítulo se presenta los saberes educativos, respaldados por una base epistémica mapuche que se constituye en lo social y cultural a partir de la educación familiar y escolar. El segundo capítulo presenta la metodología utilizada, cuya particularidad es estar orientada a los sujetos y su contexto, que permite indagar los conocimientos que constituyen en el contexto familiar y que se relacionan con elementos sociales, culturales, simbólicos y espirituales. En el tercer capítulo presenta resultados testimoniales de los kimches, quienes otorgan una evidencia empírica acerca de los elementos conceptuales, procedimentales y actitudinales que configuran el kimeltuwün. El cuarto capítulo presenta el análisis de los conocimientos educativos mapuches, donde se evidencian distintos elementos, como los kimches evidencian el conocimiento mapuche y escolar. Se demuestra que el conocimiento mapuche en el medio escolar se descalifica y se le categoriza como no científico, aun cuando aporta a la innovación científica-tecnológica y la influencia del territorio, la geografía, el lenguaje y las ciencias en general. El quinto capítulo presenta una propuesta de formación docente en el entendido que la educación intercultural ha sido pensada de forma compensatoria, debido a la baja calidad y monoculturización de educación indígena e instrumentalizada con el propósito de dominación. En este sentido, se presenta como una respuesta al desafío epistemológico, la interculturalidad como un proyecto en construcción, en donde el diálogo entre los sujetos de culturas diferentes debe darse en el contexto del pluralismo epistemológico y no desde el enfoque eurocéntrico dominante.

La lectura y análisis del libro ofrece al lector una oportunidad epistemológica, para interpelar la propia racionalidad y cómo esta se ha accionado en los contextos en los que le ha correspondido participar, ya sea como autoridad política, profesor, estudiante, apoderado o solo como actor social. Ofrece también una revisión histórica de cómo se ha impuesto una racionalidad eurocéntrica monocultural por sobre otra que ha logrado una doble racionalidad educativa, aprendiendo del mundo occidental a partir de los procesos de escolarización. Asimismo, reconoce la existencia de sociedades y culturas distintas que pueden llegar a comprensiones desde un enfoque intercultural, En este sentido queda una invitación abierta para la formación de nuevos docentes bajo la doble racionalidad educativa, que sin lugar a dudas compromete a distintos estamentos sociales y la apertura de los actores sociales que allí participan desde el diálogo de saberes.

Viviana Alejandra Zapata Zapata

Universidad Católica de Temuco (Chile) viviana.alejandra.zapata@gmail.com 